\title{
Spermatomania-the English response to Lallemand's disease
}

\author{
Dominic Hodgson MSc FRCSEd
}

J R Soc Med 2005;98:375-379

Spermatorrhoea, the involuntary loss of semen, is in Western medicine a complaint peculiar to the 19th century. The disease was championed by Professor Claude-François Lallemand, from Montpellier. In 1835, citing masturbation as a major cause, he wrote that the condition 'degrades man, poisons the happiness of his best days, and ravages society'. In England, for fifty years, doctors, patients and social commentators alike took a frenzied interest in the condition. It was only at the end of the century, when the likes of Sir James Paget questioned the very existence of spermatorrhoea, that it faded from prominence.

\section{ONAN, ONANIA, ONANISM}

The medical profession's attitude to masturbation, and indeed that of society in general, has changed immeasurably over the history of civilization. What is a constant, though, is a very high regard for semen. Ancient Ayurvedic texts, for example, teach that it takes 40 meals to make one drop of blood, 40 drops of blood to make one drop of bone marrow and 40 drops of bone marrow to make one drop of semen. ${ }^{1}$ Hippocratic and Galenic attempts to rebalance the humours by masturbation were encouraged by physicians even beyond the Enlightenment. However, fierce criticism of this practice would come in the form of the influential pamphlet Onania, ${ }^{2,3}$ published in 1710 and running to over twenty editions over the next half-century. The anonymous author's arguments, against 'the heinous sin of self pollution', were essentially theological. The consequences, as befell Onan in the book of Genesis, were direful: 'In some it has been the Cause of fainting Fits and Epilepsies; in others of Consumptions; and many young Men, who were strong and lusty before they gave themselves over to this Vice, have been worn out by it, and by its robbing the Body of its balmy and vital Moisture, without Cough or Spitting, dry and emaciated, sent to their Grave'. There followed a suggestion that masturbation might cause what would become known as spermatorrhoea: 'In others again, whom it has not kill'd, it has produc'd Nightly and excessive Seminal Emissions'. (On the matter of Onan it seems that the author was misinterpreting the biblical text: the 'sin' for

Guy's Hospital, London SE1 9RT, UK

E-mail: dominichodgson@hotmail.com which Onan was punished was not masturbation but the use of coitus interruptus to avoid impregnating his late brother's wife as duty required. ${ }^{4}$ )

The cure of self pollution was essentially to follow the author's example of godliness. Further assistance, however, was advertised at the end of the book. The 'strengthening tincture' and 'the prolific powder' were available only from the publisher.

If Onania gave opponents of masturbation a theological base, the publication of Onanism in 1766 added scientific clout. ${ }^{5}$ Written by the Swiss physician Samuel Tissot (1728-1797) and quickly translated into English, this was a physiologically reasoned argument. Tissot maintained like others that semen is precious, but differentiated between the circumstances of its loss. Thus, 'if the dangerous effects of too abundant a discharge of this humour depended only upon the quantity, or were the same when the quantities were equal, it would be of little importance, in a physical sense, whether the evacuation was occasioned by [coitus, wet dreams or masturbation]'. However, when 'the subject authorizes such licences ... direful effects ... are still more dreadful when the same quantity has been dissipated in an unnatural manner'.

He went on to give eight reasons for this. One of these was the suggestion that masturbators can develop 'impotency, through a defect of erection, and a simple gonorrhoea, because the relaxed parts suffer the real semen to escape as soon as secreted'. And this 'is mistaken, because it is not suspected, and ill treated because it is mistaken. I might easily refer to commentators, to produce examples of this disorder being treated for another'. This was a criticism of colleagues that would be made by subsequent writers on spermatorrhoea.

\section{LALLEMAND'S DISEASE}

For 70 years after the publication of Onanism little was written on the subject of involuntary loss of semen. In 1782 Wichmann, a German, wrote De Pollutione Diurna, ${ }^{6}$ which was translated from Latin into French by Saint-Marie in $1817 .^{7}$ Saint-Marie was from Montpellier, as was the most influential writer on the subject, Claude François Lallemand, who published in 1835. 


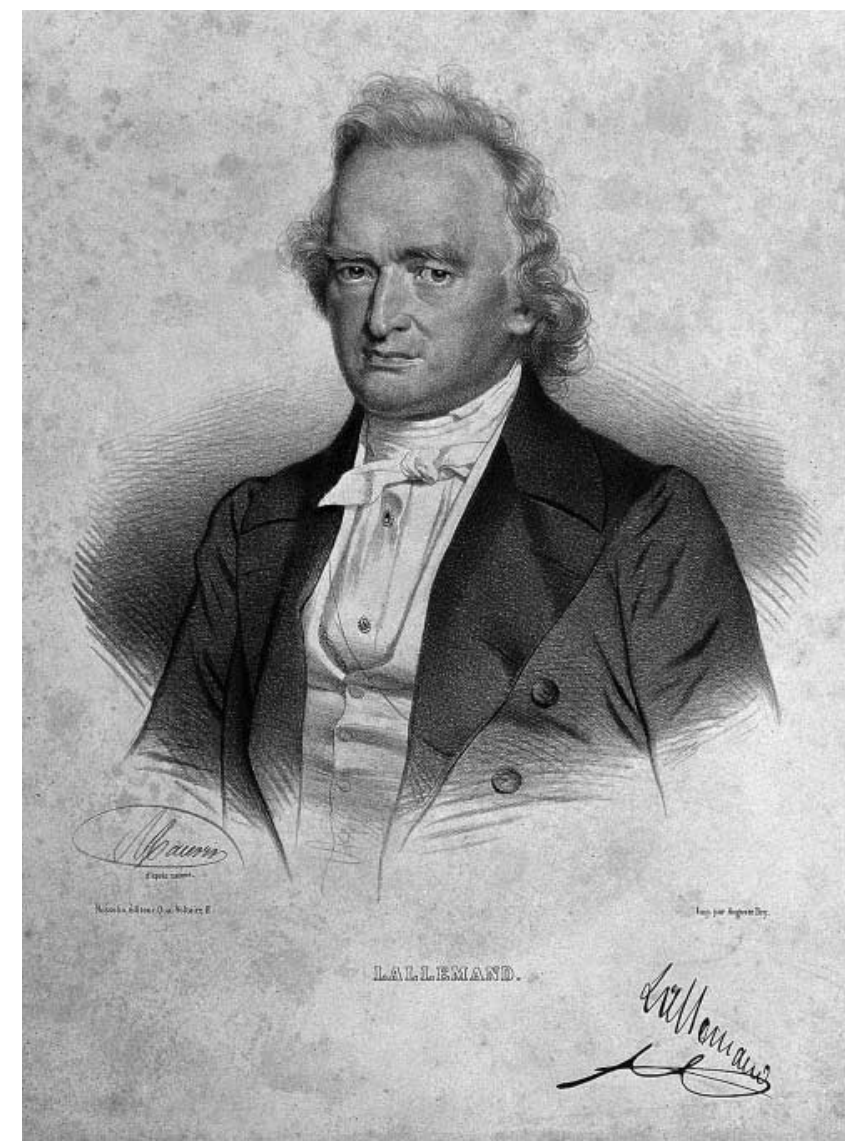

Figure 1 Claude François Lallemand (1790-1853)

Lallemand (1790-1853) (Figure 1) was a professor in the faculty of medicine, and his colleagues included Broussais. His Practical Treatise recorded 150 cases, encountered over 14 years, in which 'involuntary seminal discharges were sufficiently serious to disorder the health of patients considerably, and even sometimes, to cause death'. His work, he explained, showed 'how frequent, important, and difficult of detection, are involuntary seminal discharges, and to what deplorable errors of treatment they daily give rise'. This was 'a disease that degrades man, poisons the happiness of his best days, and ravages society'.

More than a decade passed before this work appeared in English. ${ }^{8}$ Lallemand's translator, Henry J McDougall from University College Hospital, bemoaned the lack of interest amongst colleagues, leaving patients 'prey to the balsam selling quacks'. He continued, 'Had similar opinions been held respecting syphilis - a subject quite as repugnant to English feelings as spermatorrhoea - what misery would have been entailed on the human race!'. McDougall concluded his preface, 'If through the medium of the following pages, the Profession become more fully acquainted with, and consequently better able to relieve, one of the most distressing disorders that affect mankind, I have appropriated to the subject has not been entirely misspent'. Four deaths were reported in those mistreated by misinformed colleagues. Others, lucky enough to be seen in time by Lallemand, fared better. His most celebrated treatment was cautery of the prostatic urethra.

\section{EARLY REACTION IN ENGLAND}

In truth, Lallemand's work was better known across the Channel than McDougall had suggested for Mr Benjamin Philips, from the Westminster school of medicine, wrote in the London Medical Gazette of 6 cases, in two instalments in December 1842 and January $1843 .{ }^{9}$

For 11 years he had been using caustic to cure the disease, acknowledging Lallemand's contribution while suggesting that 'opinions expressed in a foreign language are comparatively little read'. He was publishing his experiences 'in the hope that when confidence in the plan of treatment becomes more widely spread, some effort will be made to rescue this very distressing class of cases from the fangs of those harpies whose dens are daily advertised in the public press'. The first instalment recorded only one case, that of a man of 22 complaining of a weak heart, sick stomach and loss of weight and strength. Philips wrote how, on seeing the patient for the first time, he 'was struck with the apparent languor, the downcast, unquiet look, and hypochondrical expression of the patient, and my suspicion was at once awakened as to the cause of this state of things. I requested his mother, who accompanied him, to leave the room; when I told him at once that the cause of his present discomfort was the abuse of his sexual organs'. The patient admitted that 'living in the country, and being a good deal alone, about four years before he began to addict himself to masturbation'. And now he 'could not hold an ordinary conversation with a young woman without a continuous discharge of spermatic fluid'. He had sought medical help, and had been advised to 'go with women'. Philips continued, 'into the question of the morality of this advice I need not enter, but in other respects the advice was not prudent. It is almost certain that in the state of the sexual organs induced by excessive masturbation, erection would be incomplete, emission almost immediate, and connexion impracticable'. However, the patient 'proceeded to the haunts of infamy', where, 'connexion was attempted, but without success', making him desperate.

He was told to stop masturbating, but within a month had had nine discharges, two while talking to women. Of this second visit, Philips noted that 'upon proceeding to examine the urethra, the same cowardly dread of pain which is common in people with those habits was strongly shown'. A bougie was passed up the urethra and 'at arriving at some distance beyond the curvature, he regularly screamed out'. Philips 'determined to blunt the sensibility 
at this point by applying upon it lunar caustic'. A week later Philips found the patient much improved in his spirits: 'a more complete erection of the penis than had been known for upwards of a year had occurred on the morning he saw me'. A second application of caustic further decreased the discharges. Philips did not see the patient again but concluded, 'it is fair to suppose all has gone well'.

In his second instalment Philips noted, 'Since the publication of the first part of this paper, I have been painfully impressed with the conviction that the evil is more widespread than I had before conceived'. And 'almost every morning I have several applicants for relief, but with two or three exceptions they have been either medical men or medical students'. He had also received letters 'from patients expressing their complete inability to make themselves known to any human being'. He described further cases, including a medical man who, 'during his school-days had addicted himself to masturbation' and a man whose life, to use his own expression, 'seemed to be leaking away'. They were both successfully treated with caustic.

Mr TB Curling, from the London Hospital, also wrote on the subject in 1843: 'It is to Lallemand that we are indebted both for showing the great value of caustic treatment of this complaint, and for devising an improved instrument for making the application' ${ }^{10}$

McDougall neglected to mention a highly critical review of the second French edition, published in $1843 .{ }^{11}$ This voiced the opinion that Lallemand's notions as to the frequency of involuntary emissions 'are certainly exaggerated', though it did acknowledge the efficacy of Lallemand's caustic remedy. Harsher criticism followed: 'On the subject of masturbation, M. Lallemand gives a large amount of details, many of which are scarcely fitted to appear in an English dress, even though in the pages of a professional review'. And

'we have been astonished and displeasured, we had almost said disgusted, at the inconsiderate endeavour of the author to father almost every symptom; every ailment which individuals may labour under, on involuntary seminal emissions, the consequences of inordinate venery or still more vicious habits. If $\mathrm{M}$. Lallemand were to be credited, every man who has a melancholy abstracted air, who is hypochondriac, is somewhat unsocial, who, with usual care, eschews vinous or spirituous drinks, etc, ought to be suspected to labour under involuntary seminal discharges! What an imprudent and injurious and ridiculous exaggeration is this!'.

At the same time, however, resounding support for Lallemand emerged in The Lancet ${ }^{12}$ (a further 34 articles on the subject would be published in that journal over the next two decades). Mr GN Dangerfield stated that emission could occur merely at the sight of a female, and 'conscious of this wretched condition, and fearing discovery, he prefers solitude'. At length 'epilepsy, catalepsy, mania or some other disease of the nervous system, makes its appearance, and the patient is relieved from his horrid state of existence by a premature death the cause of which has been frequently overlooked by his unsuspecting physician'. Dangerfield noted that 'Lallemand almost invariably attributes it [spermatorrhoea] to masturbation, and in the climate in which he resides such propensities we believe to be more common than in this country; for there is scarcely a school either in the south of France or Italy in which this horrid and disgusting practice is not involved in to an incredible extent'.

\section{SPERMATOMANIA}

In $1851 \mathrm{McD}$ ougall, in his preface to the English translation of the second edition wrote, 'The manner in which my translation has been received. . . has convinced me that I was right in undertaking the task, and has afforded me high gratification'. For much of the next 50 years there did indeed appear to be a great appreciation for the extent and seriousness of the subject, and respect for its leading exponent as well as contempt for the role of non-medically qualified practitioners. Mr JL Milton wrote in The Lancet, 'It has always appeared strange to me that this affection should remain abandoned by the profession to a few solitary specialists, and for the benefit of the vile harpies who prey on this class of victims. Surgery, which has vested so much from empiricism and ignorance, seems disposed to yield up this, as if it were debatable land, to chance, philosophy, utter neglect or quackery'. ${ }^{13}$ Henry Thompson, formerly of University College Hospital London, was more optimistic. He praised Lallemand for providing 'among the most valuable remedies for what were, before his time, some of the most intractable, and often, on this very account, the most neglected, affections it was the lot of the surgeon to have presented to his notice. But the neglect which, it must be confessed, these cases have, and most undeservedly so, to some extent, received, is daily becoming more a thing of the past'. ${ }^{14}$ Sufferers had been 'victims of the most gross, heartless, and costly deceptions. M. Lallemand, however, has done much, and others have followed in his path, to give this subject its due weight, and, to call the serious attention of the profession to it'. Milton offered further treatment options, including the four-pointed urethral ring (Figure 2) which would 'produce no uneasiness till erection comes on, when the patient, roused by the pricking can jump out of bed and thus arrest an impending emission'. ${ }^{15}$

Perhaps the best-known 19th century British writer on sexual matters was William Acton. ${ }^{16}$ In Functions and 


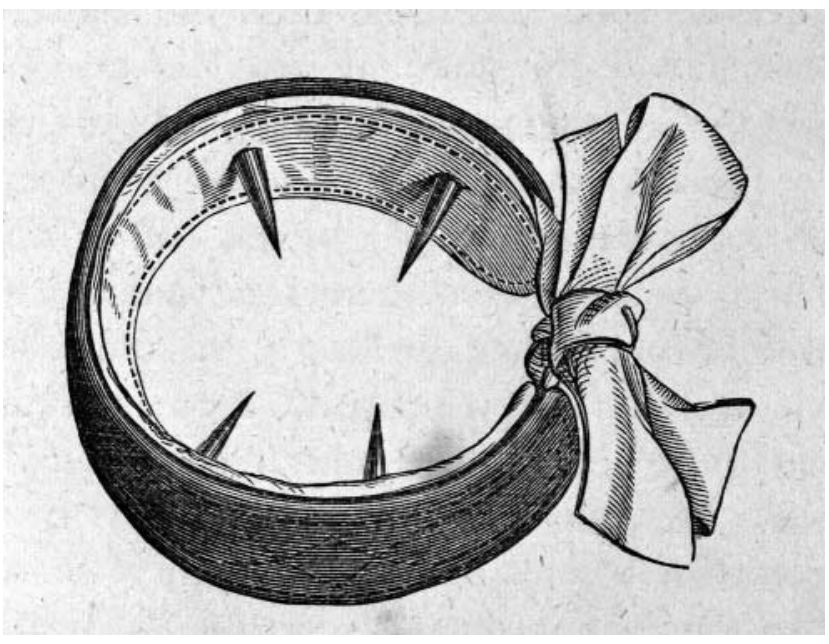

Figure 2 Milton's four-pointed urethral ring

Disorders of the Reproductive Organs, ${ }^{17}$ Acton considered the 38 pages on spermatorrhoea to be 'one of the most important, interesting, and laborious sections it has been my task to write'. He borrowed freely from Lallemand's On Involuntary Seminal Discharges, a work of which he could not 'speak in too high terms'. He too complained that, because of the neglect of the profession, 'the subject has become the domain of the veriest quacks', and 'that patients, fully aware of this, apply to these parties in the belief that the complaints are neglected by the well-educated surgeon'.

One of Acton's themes was the central effects of the disorder. 'I am inclined to think that when the system suffers, and when the constitution becomes shattered, as it often does, that the mischief arises in great part from the exhaustion of the nervous system, rather than the mere evacuation of so much semen'. His reasoning was that 'Many of the worst constitutional symptoms of spermatorrhoea may be seen in little children whose testicles do not and have not yet secreted semen, but who have learnt the evil habit of tickling the genital organs'. And 'Women sometimes labour under constitutional symptoms similar to those of men who have been victims of spermatorrhoea'. He was 'convinced that too much stress has been laid on the mere loss of semen, and too little importance placed on the drain on the nervous system'. Ultimately, though, Acton acknowledged the value of Lallemand's cauterizing instrument in difficult cases: 'in twenty years, during which he was daily in the habit of using the device, he asserts, that he never saw any ill consequence from the treatment, and I can fully bear out this statement, as far as my own experience is concerned'.

\section{WHAT GOES UP...}

An early voice of caution against the seeming pro-Lallemand majority was that of Mr FB Courtenay. He wrote:
'I can arrive at no other conclusion than that too prevalent idea existing in the profession, that to Spermatorrhoea are to be traced most of the instances of sexual debility and derangement of the generative system, of which patients so frequently complain, is a professional fallacy, and the like belief amongst patients nothing more or less than a popular delusion, pregnant with fearful sufferings to those who, labouring under it, are induced to submit to the cruel, dangerous, and inefficient method of cauterization recommended by M. Lallemand, or the caustic injections treatment adopted by others'. ${ }^{18}$

Concluding his pamphlet he warned

'anyone who may chance to read this little book, amongst the thousands of inexperienced youths who are now suffering under fearful mental despondency in consequence of having fallen in with some of the vile books published by the quacks, do not allow yourselves to be frightened by the exaggerated representations contained in them respecting the ill consequences resulting from your youthful indiscretions, and still less, if you value your future health and happiness, consult with such men'.

At the Harveian Society in $1871 \mathrm{Mr}$ George Gascoyen declared, 'with regard to the condition where there is said to be a constant loss of semen without the cognisance of the patient, I have never met with an example of it'. Of his colleagues who were enthusiasts he said

'these benefactors of the human race invoke Lallemand as their high priest; they quarry in his book for material for their own, and shelter themselves under the shadow of his name. Thanks to their popular expositions of his work, and their widely spread advertisements, the male portion of the public has become almost as familiar with the word spermatorrhoea as it has with gonorrhoea; whilst the symptoms of the disease and the awful ending foreshadowed for those who decline the assistance of the disinterested authors of these pamphlets are better known and hardly less dreaded than those of phthisis itself.' 19

Mr W Jacobsen, of Guy's Hospital, opined that the term spermatorrhoea should be done away with: ${ }^{20}$

'thanks to writers like Lallemand, and others also, [who] have too quickly copied his over-coloured picture, and thanks also to the too cursory way in which the subject has been treated by most of our great surgical writers, this word spermatorrhoea has become to the public a 
term of terror, and yet of mystery, implying as it does to them, obscure "nervous debility", insidious in its origin and certainly disastrous in its ending. It is even a worse term, not only because it is thus abused by the public, but because it has become a source of ill-gotten gain to many a cheat and a charlatan. But it is most of all objectionable because no such condition, as usually understood by it, exists'.

Perhaps the most damning comment comes from one of the most revered surgeons of the 19th century, Sir James Paget (1814-1899). Jacobsen quotes Paget as declaring:

'First amongst these false teachers is Lallemand. His picture of Spermatorrhoea in its complete form is a description of something which I believe to be unknown amongst Englishmen. It may be that there is no such disease in France; a wild imagination may have suggested it, but, whether it be found in France or not, I believe you will never see it here... . To many others, with as good opportunities as myself for seeing rare and severe cases, they are completely unknown; and I observe that English writers in this subject, when they wish to tell the worst things to which spermatorrhoea can be said to lead, speak, not from their own observation, but from what they believe to have been Lallemand's'. ${ }^{20}$

\section{AND FINALLY...}

Very little has been heard of spermatorrhoea in the West in the past century. The same does not apply, however, for Eastern cultures. Dhat syndrome 'comprises vague somatic symptoms of fatigue, weakness, anxiety, loss of appetite, guilt and sexual dysfunction attributed by the patient to the loss of semen in nocturnal emissions, through urine and masturbation', ${ }^{21}$ and has been described as a 'sex neurosis of the Indian subcontinent'.22

\section{REFERENCES}

1 Bhugra D, Buchanan A. Impotence in ancient Indian texts. Sexual Marital Ther 1989;4:87-92
2 Stolberg M. Self-pollution, moral reform, and the venereal trade: notes on the sources and historical context of Onania. J Hist Sexuality 2000;9:37-61

3 Anonymous. Onania, or the Heinous Sin of Self Pollution, and all its Frightful Consequences, etc, 6th edn. London: T Crouch, 1722

4 Roberts F. The sin of Onan. J R Soc Med 2000;93:275

5 Tissot SAD. Onanism: or, a Treatise upon the Disorders produced by Masturbation, or, the Dangerous Effects of Secret and Excessive Venery (translated by A Hume). London: J Pridden, 1766

6 Wichmann IE. De Pollutione Diurna. Göttingen: Dietrich, 1782

7 Saint-Marie E. Dissertation sur la Pollution Diurnal Involuntaire. Lyons: Reyman, 1817

8 Lallemand C. A Practical Treatise on the Causes, Symptoms, and Treatment of Spermatorrhoea (translated and edited by $\mathrm{HJ}$ McDougall, 2nd edn). London: Churchill, 1851

9 Philips B. Observations on seminal and other discharges from the urethra. Med Gazette 1842-1843;31:451-6, 584-8

10 Curling TB. A Practical Treatise on Diseases of the Testis, and of the Spermatic Cord and Scrotum. London: Highley, 1843

11 Forbes J, ed. V.M. Lallemand on involuntary seminal discharges. Br For Med Rev 1843;30:346-67

12 Dangerfield GN. The symptoms, pathology, causes, and treatment of spermatorrhoea. Lancet 1843;41:210-16

13 Milton JL. On the nature and treatment of spermatorrhoea. Lancet 1854;63:243-6

14 Thompson H. Nitrate of silver in spermatorrhoea. Lancet 1852;59: 89-91

15 Milton JL. On the Pathology and Treatment of Spermatorrhoea, 12th edn. London: Renshaw, 1887

16 Hart G, Wellings K. Sexual behaviour: in sickness and in health. BMJ 2002;324:896-900

17 Acton W. Functions and Disorders of the Reproductive Organs in Youth, Adult Age and Advanced Life, 2nd edn. London: Churchill, 1871

18 Courtenay FB. On Spermatorrhoea: How to Treat it and Cure it with Practical Observations on the Professional Fallacies and Popular Delusions which Prevail in Relation to its Nature, Consequences and Treatment, 7th edn. London: Bailière, Tindall \& Cox, 1869

19 Gascoyen GG. On spermatorrhoea and its treatment. Lancet 1872;99:67-9

20 Jacobsen WHA. The Diseases of the Male Organs of Generation. London: Churchill, 1892

21 Sumathipala A, Siribaddana SH, Bhugra D. Culture-bound syndromes: the story of dhat syndrome. Br J Psychiatry 2004; 184:200-9

22 Chadda RK, Ahuja N. Dhat syndrome, a sex neurosis of the Indian subcontinent. Br J Psychiatry 1990;156:577-9 